\title{
GAMBARAN KINERJA KARYAWAN DI RUMAH SAKIT SWASTA X DI DENPASAR TAHUN 2016
}

\author{
I Gusti Putu Ayun Widanianti*, Ketut Suarjana \\ Program Studi Kesehatan Masyarakat Fakultas Kedokteran Universitas Udayana \\ *Email: ayunwidanianti@yahoo.co.id
}

\begin{abstract}
ABSTRAK
Tujuan dari penelitian ini adalah untuk memahami kinerja karyawan di salah satu rumah sakit swasta pada tahun 2016. Penelitian ini adalah penelitian kuantitatif deskriptif dengan desain cross sectional. Teknik pengambilan sampel menggunakan random sampling (probability sampling), dengan menggunakan teknik proportional stratified random sampling dengan jumlah sampel 86 orang. Data dianalisis dengan analisis bivariat menggunakan chi-square dengan $\alpha=0,05$. Hasil penelitian ini mengungkap sekitar 51,16\% (44 orang) memiliki kualitas kerja minor dari 86 responden. Responden dengan kualitas kerja yang baik adalah 51,16\% (44 orang). Efektivitas minor responden adalah 65,12\% (56 orang). 51,16\% (44 orang) memiliki kebiasaan tepat waktu yang buruk, dan responden dengan independensi rendah adalah 62,79\% (54 orang). Perbedaan proporsi hasil yang bermakna secara statistik status pekerjaan responden dengan kualitas karyawan adalah $(p=0,013)$. Ada perbedaan proporsi yang bermakna secara statistik antara latar belakang pendidikan responden dan efektivitas $(\mathrm{p}=0,044)$, hasil uji analisis dalam proporsi yang berbeda antara latar belakang pendidikan responden dan tepat waktu adalah $(\mathrm{p}=0,10)$. Hasil analisis uji coba pada proporsi umur responden yang berbeda dengan independensi kerja adalah $(\mathrm{p}=0,047)$. Kesimpulan dari penelitian ini adalah setiap hasil penelitian ini terhadap kinerja sub-variabel, ini menunjukkan total dari hasil kinerja karyawan secara umum, yaitu 52,33\% (45 orang) dari 86 responden yang berarti kinerja karyawan dapat dikategorikan baik. Beberapa saran yang disarankan dalam penelitian ini, mereka meningkatkan kualitas kerja dan menggunakan teknologi, dana, dan semua peralatan di rumah sakit diperlukan untuk menyelesaikan pekerjaan.
\end{abstract}

Kata Kunci : Performa, karyawan, rumah sakit

\begin{abstract}
The purpose of this research is to understand the employees' performance at private hospital in 2016. This research is a descriptive quantitative studies with cross sectional design. The sampling technique used random sampling (probability sampling), by using proportionate stratified random sampling technique with 86 persons as the samples. Data was analised with bivariate analysis using chi-square with $\alpha=0.05$. The result of this research reveal around $51.16 \%$ (44 persons) have a minor working quality out of 86 respondents. Respondents with good working quality are $51.16 \%$ (44 persons). The minor effectiveness of respondents is $65.12 \%$ (56 persons). $51.16 \%$ (44 persons) have a bad punctual habit, and respondents with low independence are $62.79 \%$ (54 persons). The different valuable proportion result statistically employment status of respondents with employees quality is $(\mathrm{p}=0.013)$. There is difference valuable proportion statistically between the education background of respondents and effectiveness in $(\mathrm{p}=0.044)$, the result of analysis trial in different proportion between education background of respondents and punctual is $(p=0.10)$. And the result of trial analysis in different proportion of age of the respondents with working independence is $(p=0.047)$ The conclusion of this research is every results of this research towards sub-variable performance, it shows the total from employees performance result generally, which is $52.33 \%$ (45persons) from 86 respondents that means the employees performance can be categorized as good. Some advices are suggested in this study, they are improving the quality of work and using the technology, funding, and all of the equipments in the hospital are needed to finisih a job.
\end{abstract}

Keywords: performance; employee; private hospital 


\section{PENDAHULUAN}

Rumah sakit merupakan salah satu lembaga yang bergerak dibidang pelayanan jasa kesehatan dengan tanggung jawab memberikan pengobatan, memberikan perawatan, mengusahakan kesembuhan dan kesehatan pasien, serta mengupayakan pendidikan hidup sehat bagi masyarakat. Pengertian rumah sakit menurut Menteri Kesehatan Republik Indonesia Nomor 340/MENKES/PER/III/2010, dikemukakan bahwa rumah sakit adalah institusi pelayanan kesehatan yang menyelenggarakan pelayanan kesehatan perorangan secara paripurna yang menyediakan pelayanan rawat inap, rawat jalan, dan gawat darurat. Rumah Sakit Umum adalah Rumah Sakit yang memberikan pelayanan kesehatan pada semua bidang dan jenis penyakit (Puti, 2013).

Dalam pengorganisasian rumah sakit tidak akan terlepas dari sumber daya manusia (SDM) yang ada dalam organisasi rumah sakit tersebut. Manajemen sumber daya manusia pada hakekatnya merupakan bagian integral dari keseluruhan manajemen rumah sakit dan sumber daya manusia adalah merupakan modal dan kekayaan yang terpenting dari seluruh kegiatan yang dilaksanakan di rumah sakit. Saat ini keberhasilan sebuah rumah sakit sangat ditentukan oleh pengetahuan, keterampilan, kreativitas, dan motivasi staff dan karyawannya.

Menurut Hasibuan (2009) sumber daya manusia adalah kemampuan terpadu dari daya pikir dan daya fisik yang dimiliki individu. Perilaku dan sifatnya ditentukan oleh keturunan dan lingkungannya, sedangkan prestasi kerjanya dimotivasi oleh keinginan untuk memenuhi kepuasannya.

Sumber daya manusia selalu ingin meningkatkan prestasinya di dalam dunia kerja untuk mencapai kepuasan kerjanya. Jika kepuasan kerja tercapai maka sumber daya manusia tersebut dapat dengan nyaman menikmati pekerjaannya sendiri.Kepuasan kerja adalah perasaan seseorang terhadap pekerjaannya. Ini berarti bahwa konsepsi kepuasan kerja melihatnya sebagai hasil interaksi manusia terhadap lingkungan kerjanya.

Kepuasan kerja dan keberhasilan suatu organisasi sangat dipengaruhi oleh kinerja individu karyawannya. Kinerja dalam organisasi merupakan jawaban dari berhasil atau tidaknya tujuan organisasi yang telah ditetapkan. Menurut Ilyas (2002) kinerja adalah penampilan karya personal baik kuantitas maupun kualitas dalam suatu organisasi.

Dari data hasil survey kepuasan kerja karyawan di salah satu rumah sakit swasta tahun 2014 di dapatkan 58\% yang puas dan $42 \%$ yang tidak puas dari 472 orang karyawan dengan standar target pencapaian $50 \%$. Namun ternyata masih cukup banyak terjadi kesenjangan yang kurang sesuai dengan idealisme, masih ada beberapa kelemahan yang masih ditunjukkan oleh karyawan/pegawai dimana mereka kurang termotivasi dengan pekerjaannya. Ada yang tidak tepat waktu saat masuk kantor, menunda tugas kantor, kurang disiplin waktu dan tidak bisa memanfaatkan sarana kantor dengan baik. Hasil survey kepuasan kerja tersebut 
memang sudah mencapai target, akan tetapi dari hasil wawancara yang dilakukan dengan beberapa karyawan, mereka menyatakan kurang puas khususnya kurang puas dengan kompensasi, pekerjaan itu sendiri dan promosi kerja, ketidakpuasan tersebut akan berdampak terhadap kinerja. Dari latar belakang tersebut diatas, maka peneliti bertujuan untuk mengetahui gambaran kinerja karyawan di salah satu rumah sakit swasta tahun 2016.

\section{METODE}

Penelitian ini merupakan penelitian deskriptif kuantitatif dengan rancangan penelitian yang digunakan adalah cross sectional karena pengumpulan data untuk variabel bebas dan variabel tergantung dilakukan secara bersamaan pada satu saat atau satu periode waktu (Sugiyono, 2010). Dalam penelitian ini yang menjadi populasi adalah seluruh pegawai di salah satu rumah sakit swasta sebanyak 472 orang.

Populasi penelitian terbagi ke dalam beberapa unit, sampel diambil berdasarkan random sampling (probability sampling),

Tabel 1Distribusi Frekuensi Karakteristik Responden

\begin{tabular}{|c|c|c|}
\hline Karakteristik & $\mathbf{F}$ & $\begin{array}{c}\text { Persentase } \\
(\%)\end{array}$ \\
\hline \multicolumn{3}{|l|}{ Tingkat Pendidikan } \\
\hline SMA/SMK & 7 & 8,14 \\
\hline D1 & 1 & 1,16 \\
\hline D2 & 2 & 2,33 \\
\hline D3 & 28 & 32,56 \\
\hline S1 & 47 & 54,65 \\
\hline S2 & 1 & 1,16 \\
\hline \multicolumn{3}{|l|}{ Jenis Kelamin } \\
\hline Laki-laki & 21 & 24,42 \\
\hline Perempuan & 65 & 75,58 \\
\hline
\end{tabular}

dengan teknik proportionate stratified random sampling karena dalam populasi penelitian ini mempunyai unsur yang tidak homogen dan berstrata secara proporsional. Berdasarkan rumus untuk mencari jumlah sampel per unit, total dari masing-masing unit di dapat sampel 89 orang, tetapi 3 orang tidak mengisi kuesioner karena bukan termasuk karyawan sehingga sampel yang di dapat menjadi 86 orang. Analisa data dilakukan dengan univariat dan bivariat dengan menggunakan chi-square dengan $p=$ 0.05 .

\section{HASIL}

\section{Karakteristik Responden}

Tabel 1 menunjukkan karakteristik tenaga medis dan non medis di Salah satu rumah sakit swasta berdasarkan tingkat pendidikan, jenis kelamin, umur, lama bekerja, jabatan dan status kepegawaian 


\begin{tabular}{|c|c|c|}
\hline \multicolumn{3}{|l|}{ Umur } \\
\hline 20-29 tahun & 49 & 56,98 \\
\hline 30-39 tahun & 27 & 31,40 \\
\hline 40-49 tahun & 6 & 6,98 \\
\hline$>50$ tahun & 4 & 4,65 \\
\hline \multicolumn{3}{|l|}{ Jabatan (Bagian) } \\
\hline Staff & 71 & 82,56 \\
\hline Kepala & 15 & 17,44 \\
\hline \multicolumn{3}{|l|}{ Status Kepegawaian } \\
\hline Tetap & 52 & 60,47 \\
\hline Kontrak & 34 & 39,53 \\
\hline \multicolumn{3}{|l|}{ Lamanya Bekerja } \\
\hline$<1$ tahun & 10 & 11,63 \\
\hline 1-5 tahun & 58 & 67,44 \\
\hline$>5$ tahun & 18 & 20,93 \\
\hline
\end{tabular}

Berdasarkan tabel di atas dapat diketahui bahwa mayoritas responden adalah perempuan (75,58\%), berada pada kelompok umur 20-29 tahun (56,98\%), mempunyai jabatan staf yaitu sebesar $(82,56 \%)$ status kepegawaian sebagai pegawai tetap sebesar $(60,47 \%)$ dan lama bekerja 1-5 tahun yaitu sebesar $67,44 \%$

Distribusi Frekuensi Kinerja Responden

Tabel II menunjukkan kinerja tenaga medis dan non medis yang dikategrikan atas baik dan kurang baik.

Tabel 2 Distribusi Frekuensi Kinerja Responden

\begin{tabular}{ccc}
\hline Kinerja & F & $\begin{array}{c}\text { Persentase } \\
\text { (\%) }\end{array}$ \\
\hline Baik & 45 & 52,33 \\
Kurang Baik & 41 & 47,67 \\
\hline Total & 86 & 100,00
\end{tabular}

Berdasarkan 2 diatas dapat dilihat bahwa yang kurang kerja baik yaitu sebesar 47,67\% dari 86 responden pada penelitian ini, (41 orang). sebagian besar memiliki kinerja baik yaitu sebesar 52,33\% (45 orang), dibandingkan Distribusi Frekuensi Sub-Variabel Kinerja dengan responden yang mempunyai kinerja

Tabel 3 menunjukkan distribusi frekuensi responden berdasarkan variabel kinerja 
yaitu kualitas kerja, kuantitas kerja, kemandirian tenaga medis dan non medis efektivitas kerja, ketepatan waktu dan

Tabel 3 Distribusi Frekuensi Responden Berdasarkan Variabel Kinerja

X, maka diperoleh hasil bahwa karyawan di

\begin{tabular}{lccc}
\hline Variabel Kinerja & F & $\begin{array}{c}\text { Persentase } \\
\text { (\%) }\end{array}$ \\
\hline Kualitas & Baik & 42 & 48,84 \\
& Kurang Baik & 44 & 51,16 \\
\hline Kuantitas & Baik & 44 & 51,16 \\
& Kurang Baik & 42 & 48,84 \\
\hline Efektivitas & Baik & & \\
& Kurang Baik & 30 & 34,88 \\
& Betepatan Waktu & 56 & 65,12 \\
& $\quad$ Kurang Baik & 42 & 48,84 \\
& $\quad$ & 44 & 51,16 \\
\hline Kemandirian & Baik & 32 & 37,21 \\
& Kurang Baik & 54 & 62,79 \\
\hline
\end{tabular}

Salah satu rumah sakit swasta memiliki kinerja yang baik $(52,23 \%)$. Ini berarti dari pihak rumah sakit sudah cukup baik

Berdasarkan tabel 3, dapat dilihat bahwa dari mayoritas memiliki kualitas kerja yang kurang baik yaitu sebesar 51,16\%. Dari 86 responden sebagian besar memiliki kuantitas kerja yang baik yaitu sebesar $51,16 \%$. Berdasarkan efektivitas, sebagian besar responden memiliki efektivitas kerja yang kurang baik yaitu sebesar 65,12\%. Sedangkan berdasarkan ketepatan waktu sebagian besar memiliki ketepatan waktu kerja yang kurang baik yaitu sebesar $51,16 \%$. Dan dari kemandirian, sebagian besar responden memiliki kemandirian kerja yang kurang baik yaitu sebesar $62,79 \%$.

\section{DISKUSI}

\section{Kinerja Karyawan Rumah Sakit Swasta $X$}

Berdasarkan hasil penelitian yang dilakukan kepada karyawan di Rumah Sakit membimbing dan melatih keterampilan karyawannya untuk menyelesaikan tugas dan tanggung jawab yang diberikan oleh rumah sakit.

Selain itu kinerja juga dipengaruhi oleh karakteristik individu atau karakteristik sumber daya manusia itu sendiri untuk menghasilkan kinerja yang baik atau kurang baik. Sumber daya yang terpenting dalam organisasi adalah sumber daya manusia, orang-orang yang memberikan tenaga, bakat, kreativitas, dan usaha mereka kepada organisasi agar suatu organisasi dapat tetap eksistensinya. Mathiue \& Zajac dalam Wuryanto (2010) menyatakan bahwa karakteristik personal (individu) mencakup usia, jenis kelamin, masa kerja, tingkat pendidikan, suku bangsa, kepribadian. 
Mayoritas responden dalam penelitian ini memiliki tingkat pendidikan S1 (54,65\%). Hal ini didukung oleh pendapat dari Douglas dalam Swastika (2010) yang menyebutkan bahwa tingkat pendidikan karyawan dengan rasio akademik lebih banyak akan memudahkan dalam menerima serta mengembangkan pengetahuan dan teknologi. Semakin tinggi pendidikan akan semakin tinggi keinginan untuk memanfaatkan pengetahuan dan keterampilan. Jika dilihat dari jenis kelamin, maka dari 86 responden yang menjadi subyek dalam penelitian ini sebagian besar adalah berjenis kelamin perempuan (75,58\%). Hal ini didukung oleh pendapat dari Mowday dalam Wuryanto (2010) yang menyebutkan bahwa wanita sebagai kelompok cenderung memiliki komitmen terhadap organisasi lebih tinggi dibandingkan dengan pria. Wanita pada umumnya harus mengatasi lebih banyak rintangan dalam mencapai posisi mereka dalam organisasi sehingga keanggotaan dalam organisasi menjadi lebih penting bagi mereka.

Dari 86 responden yang dijadikan sebagai subyek penelitian di Rumah Sakit X, , paling banyak berasal dari kelompok umur 20-29 tahun (56,98\%). Hal ini didukung oleh pendapat dari Nitisemito dalam Wuryanto (2010) yang menyebutkan bahwa pegawai yang lebih muda cenderung mempunyai fisik yang kuat dan pada umumnya mereka belum berkeluarga atau bila sudah berkeluarga anaknya relatif masih sedikit sehingga diharapkan dapat bekerja keras dalam menyelesaikan pekerjaan sehari-hari.
Dari 86 responden yang dijadikan subyek penelitian di Rumah Sakit X, , paling banyak berasal dari jabatan sebagai staff yaitu 71 orang $(82,56 \%)$. Hal ini di dukung oleh pendapat dari Melayu S.P Hasibuan (2004:63), penempatan/jabatan adalah calon karyawan yang diterima pada jabatan/pekerjaan yang membutuhkan dan sekaligus mendelegasikan authority kepada orang tersebut. Menurut Marihot Tua Efendi (2002:156) penempatan/jabatan merupakan proses penugasan/pengisian jabatan atau penugasan kembali pegawai pada tugas/jabatan baru atau jabatan berbeda.

Berdasarkan status kepegawaian diperoleh hasil bahwa dari 86 responden yang menjadi subyek dalam penelitian ini, sebagian besar berstatus pegawai tetap $(60,47 \%)$. Hal ini didukung oleh pendapat dari Ghiseli dan Brown dalam Danu (2012) yang menyebutkan bahwa pegawai dengan pekerjaan yang mendasarkan pada perbedaan tingkat (golongan), sehingga pekerjaan tersebut memberikan kedudukan tertentu pada orang yang melakukannya maka sedikit banyaknya akan dapat mengubah prilaku dan perasaan pegawai dalam menyelesaikan pekerjaannya menjadi lebih baik.

Apabila dilihat dari lamanya bekerja atau masa kerja, maka dari 86 responden yang menjadi subyek dalam penelitian ini sebagian besar mempunya masa kerja selama $>1$ tahun $(67,44 \%)$. Hal ini didukung oleh pernyataan yang dikemukakan ole Kreitner dan Kinicki dalam Wuryanto (2010) yaitu bahwa masa kerja yang lama akan cenderung membuat seorang pegawai lebih merasa betah dalam suatu organisasi, hal ini 
disebabkan diantaranya karena telah beradaptasi dengan lingkungannya yang cukup lama sehingga seorang pegawai akan merasa nyaman dengan pekerjaannya.

\section{Gambaran Kinerja Karyawan Berdasarkan Sub-Variabel}

Berdasarkan hasil penelitian terhadap kualitas kerja karyawan di Rumah Sakit X, diperoleh hasil bahwa sebagian besar karyawan memiliki kualitas kerja yang kurang baik (51,16\%) dalam melaksanakan tugas dan pekerjaannya sehari-hari. Apabila dikaitkan dengan teori kualitas kerja yang dikemukakan Sumiyati (2006), berpendapat bahwa kualitas kerja artinya derajat dimana proses atau hasil yang membawa suatu aktivitas mendekati atau menuju kesempurnaan, menyangkut pembentukan aktivitas yang ideal atau mengintensifkan suatu aktivitas menuju suatu tujuan.

Berdasarkan hasil penelitian terhadap karyawan di Rumah Sakit X, mengenai kuantitas kerja diperoleh hasil bahwa sebagian besar karyawan memiliki kuantitas kerja yang baik $(51,16 \%)$ dalam mengahasilkan tugas yang telah diberikan dan terselesaikan sesuai dengan standar. Melihat teori-teori dari para ahli mengenai kuantitas kerja diatas, dapat disimpulkan bahwa Rumah Sakit X, telah berhasil meningkatkan kuantitas kerja karyawannya baik dari tenaga medis maupun non medis. Dilihat dari teori menurut Mathis dan Jackson (2002), kuantitas kerja dilakukan dengan cara membandingkan antara besarnya volume kerja yang seharusnya (standar kerja norma) dengan kemampuan sebenarnya.
Berdasarkan hasil penelitian mengenai efektivitas kerja karyawan di Rumah Sakit X, maka di peroleh hasil bahwa karyawan memiliki efektivitas kerja yang kurang baik yaitu sebesar $65,12 \%$. Ini menujukkan bahwa karyawan di Rumah Sakit X, tidak dapat melaksanakan pekerjaan secara tepat, efektif dan efisien, apabila pekerjaan tersebut dilaksanakan dengan tepat sesuai dengan yang telah direncanakan, maka jelas bahwa sesungguhnya efektivitas kerja tidak lain adalah seorang atau beberapa orang yang terdapat dalam suatu kelompok ataupun organisasi untuk dapat melahirkan suatu kegunaan atau manfaat dari apa yang dikerjakan. Sebaiknya pihak rumah sakit memperhitungkan berapa jumlah karyawan dan berapa jumlah peralatan yang harus disediakan setiap unitnya untuk mempercepat kerja karyawan. Bukan hanya itu saja, sumber dana, bahan baku, teknologi seharusnya sudah siap untuk memenuhi kebutuhan kerja karyawan, begitu juga dengan karyawan sebaiknya menyiapkan tenaga sebaik mungkin untuk menyelesaikan pekerjaan.

Dari hasil penelitian di Rumah Sakit $X$ mengenai ketepatan waktu kerja karyawan, maka di peroleh hasil bahwa karyawan di Rumah Sakit X, memiliki ketepatan waktu kerja yang kurang baik (51,16\%). Dilihat dari teori-teori para ahli yang telah dipaparkan diatas mengenai ketepatan waktu dapat disimpulkan bahwa karyawan di Rumah Sakit X, tidak memaksimalkan waktunya untuk menyelesaikan pekerjaannya, bisa disebabkan karena tidak bisa datang tepat waktu ketempat kerja dan menggunakan 
waktu bekerja untuk mengerjakan hal diluar pekerjaan yang telah diberikan oleh rumah sakit, ini berarti karyawan tidak memiliki disiplin kerja yang baik. Disiplin kerja yang baik adalah apabila karyawan mematuhi peraturan, yakni karyawan datang tepat waktu, tertib, teratur, berpakaian rapi, menggunakan perangkat kerja dengan hatihati, karyawan dapat mengikuti cara kerja yang ditentukan oleh perusahaan dan karyawan bertanggung jawab atas segala sesuatu yang berkaitan dengan pekerjaan (Ardiansyah \& Wasilawati, 2014).

Hasil penelitian terhadap karyawan di Rumah Sakit X, mengenai kemandirian di peroleh hasil yaitu kemandirian karyawan di Rumah Sakit X, memiliki kemandirian kerja yang kurang baik (62,79\%). Ini menyatakan bahwa karyawan Rumah Sakit $\mathrm{X}$, tidak mampu menjalankan fungsi kerja dan komitmen kerjanya dengan baik. Tidak percaya diri untuk mengeluarkan ide-ide yang berkaitan dengan kemajuan kerjanya.

\section{SIMPULAN}

Dari hasil penelitian ini dapat disimpulkan bahwa secara umum gambaran kinerja karyawan sebagian besar baik (51,16\%), mempunyai kualitas kerja karyawan kurang baik $(65,12 \%)$, kemandirian kerja cukup $(62,79 \%)$. dan ketepatan waktu kurang baik $(51,16 \%)$.

\section{SARAN}

Berdasarkan hasil penelitian ditemukan beberapa permasalahan yang belum terpecahkan, sehingga peneliti mengajukan beberapa saran. Saran tersebut antara lain sebagai berikut, perlu adanya penekanan mengenai pengertian akan tanggung jawab dari tugas yang diberikan dan selalu melatih keterampilan dan kemampuan karyawan agar sesuai dengan pekerjaannya, sehingga skill karyawan sesuai dengan posisi kerja dan standar pekerjaan yang diberikan dapat tercapai. Perlunya peningkatan kualitas kerja, seperti meningkatkan keahlian dan keterampilan baik melalui pendidikan dan pelatihan yang diberikan secara berkesinambungan kepada karyawan, adanya suatu pengakuan yang dapat meningkatkan semangat dan motivasi kerja karyawan serta adanya perbaikan kesejahteraan untuk karyawan. Sebaiknya pihak rumah sakit memperhitungkan berapa jumlah karyawan dan berapa jumlah peralatan yang harus disediakan untuk mempercepat kerja karyawan, serta pihak rumah sakit harus tegas memberikan sanksi bagi karyawan yang melanggar aturan dan melakukan pengawasan yang lebih ketat untuk meningkatkan kinerja karyawan.

Peneliti selanjutnya diharapkan untuk mengkaji lebih banyak sumber maupun referensi yang terkait dengan kinerja karyawan beserta faktor-faktornya agar hasil penelitiannya dapat lebih baik dan lebih lengkap lagi.

\section{DAFTAR PUSTAKA}

Hasibuan, Melayu, SP. (2004). Organisasi dan Motivasi, Dasar Peningkatan Produktifitas. Bumi Aksara. Jakarta. Hasibuan, M. (2009). Manajemen Sumber Daya Manusia. Edisi Revisi. Jakarta:

Ilyas. (2002). Kinerja (teori dan pilihan). Jakarta: Pusat kajian Ekonomi Kesehatan FKM UI.

Kemenkes. (2009). UU Nomor 44 Tahun 2009 Tentang Rumah Sakit. Jakarta: Republik Indonesia. 
Mathis, R. L \& Jackson, J.H. (2002). Manajemen Sumber Daya Manusia. Edisi Ketiga. Jakarta : Salemba Empat.

Puti, W.C. (2013). Pengaruh Kualitas Pelayanan dan Kepuasan Terhadap Loyalitas Pasien Rawat Jalan dan Rawat Inap Rumah Sakit Otorita Batam. Skripsi Fakultas Bisnis dan Manajemen Universitas Widyatama.

Sumiyati, A. (2006). Analisis Faktor-Faktor Yang Berhubungan Dengan Kinerja Kepala Ruang Rawat Inap Di Rumah Sakit Dokter Kariadi Semarang Tahun 2006. Tesis Program Pasca Sarjana Universitas Diponegoro Semarang.

Wuryanto, E. (2010). Hubungan Lingkungan Kerja dan Karakteristik Individu dengan Kepuasan Kerja Perawat di Rumah Sakit Umum Daerah Tugurejo Semarang. Tesis Fakultas Ilmu Keperawatan Kekhususan Manajemen Keperawatan. Depok. 2010.

Danu. (2012). Analisis Pengaruh Promosi Jabatan, Persepsi Keadilan Kompensasi dan Lingkungan Kerja Fisik Terhadap Kepuasan Kerja Karyawan. Universitas Diponegoro.

Swastika, G. (2010). Pengaruh Gaya Kepemimpinan Kepala Ruang Rawat Inap Terhadap Motivasi Kerja Perawat Di Badan Layanan Umum Rumah Sakit Umum Kabupaten Buleleng Tahun 2010. Program Studi Ilmu Kesehatan Masyarakat Universitas Udayana. 